\title{
Immediate postpartum intrauterine contraceptive device utilization and influencing factors in Addis Ababa public hospitals: a cross-sectional study
}

Yohannes Fikadu Geda ${ }^{1 *}$ (D), Seid Mohammed Nejaga ${ }^{2^{*}}$, Mesfin Abebe Belete ${ }^{3}$, Semarya Berhe Lemlem ${ }^{3}$ and Addishiwet Fantahun Adamu ${ }^{3}$

\begin{abstract}
Background: Postpartum intrauterine device (PPIUCD) utilization remains very low in Ethiopia beside high levels of unmet need for postpartum family planning even if nongovernmental organizations efforts to promote its use. This study investigates immediate PPIUCD utilization and influencing factors.

Methods: Institution based cross-sectional study was conducted on public hospitals of Addis Ababa city. All public hospitals which have PPIUCD service were included and systematic random sampling technique was used to select 286 participants. Data were entered using Epi Data and exported to SPSS for analysis. Bivariate and multivariate logistic regression analysis was used to determine the effect of independent variables on immediate PPIUCD utilization. Variables which have $P$-value $<0.2$ on bivariate analysis were candidate for multivariate analysis. Variables which have $P$-value $\leq 0.05$ on multivariate analysis was considered as statistically significant.

Results: Utilization of immediate PPIUCD among participants who gave birth in Addis Ababa public hospitals was $26.6 \%$ (95\%Cl: $21.3,31.8)$. Eighty one percent respondents occupation was housewife were (AOR $=0.19,95 \% \mathrm{Cl}: 0.06$, 0.67) less likely to utilize PPIUCD compared to those who have personal job. In the other hand respondents who have discuss about PPFP with their partner were 1.21 times (AOR $=1.21,95 \% \mathrm{Cl}: 1.14,25.67$ ) more likely to utilize PPIUCD compared to those who never discuss. Contrarily $81 \%$ of respondents who need partner approval were $(A O R=0.19,95 \% \mathrm{Cl}: 0.05,0.79)$ less likely to utilize PPIUCD compared to those who doesn't need approval. Respondents who have been counseled about PPIUCD were 1.13 times ( $\mathrm{AOR}=1.13,95 \% \mathrm{Cl}: 1.10,2.21$ ) more likely to utilize PPIUCD compared to those who were not counseled. Similarly respondents who have good knowledge about PPIUCD were 7.50 times ( $\mathrm{AOR}=7.50,95 \% \mathrm{Cl}$ : 4.06, 9.31) more likely to utilize PPIUCD compared to those who have poor knowledge.

(Continued on next page)
\end{abstract}

\footnotetext{
*Correspondence: nechsar@gmail.com; seidm348@gmail.com

'Department of Midwifery, Wolkite University, Wolkite, Ethiopia

${ }^{2}$ College of Health Science, Black Lion Specialized Hospital, Addis Ababa University, Addis Ababa, Ethiopia

Full list of author information is available at the end of the article
}

C C The Author(s). 2021 Open Access This article is licensed under a Creative Commons Attribution 4.0 International License, which permits use, sharing, adaptation, distribution and reproduction in any medium or format, as long as you give appropriate credit to the original author(s) and the source, provide a link to the Creative Commons licence, and indicate if changes were made. The images or other third party material in this article are included in the article's Creative Commons. licence, unless indicated otherwise in a credit line to the material. If material is not included in the article's Creative Commons licence and your intended use is not permitted by statutory regulation or exceeds the permitted use, you will need to obtain permission directly from the copyright holder. To view a copy of this licence, visit http://creativecommons.org/licenses/by/4.0/. The Creative Commons Public Domain Dedication waiver (http://creativecommons.org/publicdomain/zero/1.0/) applies to the data made available in this article, unless otherwise stated in a credit line to the data. 


\begin{abstract}
(Continued from previous page)
Conclusion: This study verifies that immediate PPIUCD utilization is high compared to other studies. Having a housewife occupation and necessity of partner approval to utilize PPIUCD have negative influences, whereas spousal discussion about PPIUCD, counseled during pregnancy and having good knowledge have positive influences on PPIUCD utilization. Therefor empowering women by the government and other organizations working on maternal health will advance immediate PPIUCD utilization.
\end{abstract}

Keywords: Immediate postpartum, Intrauterine contraceptive device, Contraception, Addis Ababa

\section{Background}

Postpartum family planning (PPFP) is defined as the use of family planning in the first 12 month following birth $[1,2]$. Fertility after birth can return as soon as 45 days after giving birth for women who are not breastfeeding $[3,4]$ and it can also occur before menses is resumed on those who don't feed breast exclusively [5].

World Health Organization (WHO) recommends spacing pregnancies by at least 24 months [6]. However, unmet need for family planning is high in the postpartum period, ranging from 32 to $62 \%$ in low and middle- income countries $[3,7,8]$. Because of unmet need, unintended pregnancy is common in postpartum period $[9,10]$. Beside this closely spaced pregnancies are expected to have adverse maternal, perinatal and infant outcomes [11, 12].

Postpartum intrauterine contraceptive device (PPIUCD) is one of the contraceptive methods which is safe and highly effective, reliable and long acting contraceptive [13, 14]. The effectiveness of intrauterine device (IUCD) as a contraceptive method is approximately 99.2 to $99.8 \%$ within the first year of use, which is better than other shorter-term reversible contraceptive methods $[15,16]$.

PPIUCD is an acceptable contraception with fewer complications [17, 18]. PPIUCD inserted just after 10 min of placental delivery is a safe, effective, and efficient method of meeting women's need for long-acting but reversible method of contraception $[19,20]$. It can be placed after abortion, vaginal delivery and during caesarian section [21].

In Ethiopia PPIUCD intervention on selected public health facility is started on 2014 even if it is not widely utilized [6]. Intrauterine device is the least utilized modern contraceptive method in Ethiopia [22]. Reasons for low utilization range from limited provision of IUCDs to a lack of staff trained in providing family planning counseling and services to preexisting biases against IUCDs among both providers and the general public $[19,23-26]$.

Unmet need of family planning among married women in Ethiopia is 22\% [22]. In addition to this $17 \%$ pregnancies were mistimed, and $8 \%$ of pregnancies were unwanted [27]. Increasing access to effective postpartum intrauterine contraceptive methods can reduce the risk of unintended pregnancy and short inter-birth intervals [28].

Postpartum unintended pregnancy is an important public health challenge in Ethiopia. Moreover there are very few studies conducted on PPIUCD in low resource setting and it is an emerging services. Understanding the level of PPIUCD utilization will provide information that can be used by policy makers and other stakeholders to improve service delivery of PPIUCD. There for this study aimed to assess immediate PPIUCD utilization and influencing factors in Addis Ababa public hospitals.

\section{Methods}

\section{Study setting and design}

This study was conducted in public hospitals of Addis Ababa. Addis Ababa is the capital city of Ethiopia. The city has 10 sub-cities and located at the geographical center of the country. According to national census annual population growth rate of Addis Ababa was 2.1\% between 1994 and 2007 and current total projected population size of $4,005,597$, out of these female population accounted $52 \%$. Women of reproductive age group among the total population are 947,855 [29].

Addis Ababa city has 13 public hospitals distributed throughout $10 \mathrm{sub}$ cities. The public hospitals in the city are Black Lion Specialized Hospital (BLSH), St Paul Hospital Millennium Medical College (SPHMMC), Amanuel Hospital (AmH), Alert Hospital (AlH), St Peter Hospital (SPH), Police Hospital (PH), Armed Force Hospital (AFH), Zewditu Memorial Hospital (ZMH), Menilik II Memorial Hospital (MMH), Ras-Desta Memorial Hospital (RDMH), Yekatite-12 Hospital (YH), Tirunesh Beijing Hospital (TBH) and Gandhi Memorial Hospital $(\mathrm{GMH})$. On the selected hospitals postnatal ward institution based crossectional study was conducted from August 25-September 30, 2019.

\section{Study subject}

All postpartum women who gave birth in Addis Ababa public hospitals were the source population. Postpartum women who have had fulfilled WHO eligibility criteria for insertion of immediate postpartum IUCD were during the study period were included. Those who have high Fever during labor and delivery, having active 
sexual transmitted diseases (STD) or other lower genital tract infection or high risk for STD, ruptured membrane for more than $24 \mathrm{~h}$ prior to delivery, known uterine abnormalities, unresolved post-partum hemorrhage or postpartum uterine atony requiring use of additional oxytocic drugs were excluded from the study in accordance with WHO exclusion criteria [30].

\section{Sample size determination, sampling technique and procedures}

The sample size was determined by using single population proportion formula. By considering 5\% margin of error, $95 \%$ confidence interval (CI), $21.6 \%$ proportion of immediate PPIUCD practice from a study done in Sidama Zone, southern Ethiopia [31], and none response rate of $10 \%$ making final sample size of 286 .

From the total public hospitals in Addis Ababa city all hospitals providing PPIUCD service were included in this study. Hospitals providing PPIUCD service are BLSH, SPHMMC, ZMH, MMH, and GMH. To select study participants, the total sample size was allocated proportionally to each included hospital based on the average number of monthly delivery service. Postpartum women's in each included hospitals were selected using systematic random sampling technique. To select individual participant, order of delivery record book was used and interval of selection was calculated based estimated average monthly client flow to each hospital (Fig. 1).

\section{Variables}

Immediate Postpartum intrauterine contraceptive utilization was dependent variable of this study. Sociodemographic characteristic (age, marital status, occupation, educational status, religion); knowledge, attitude, obstetric characteristics (birth interval, decision to use family planning, number of birth and children, planned/unplanned Pregnancy); health service related (numbers of Antenatal care visits, Family Planning Counseling during Antenatal care and delivery setting, previous Family Planning experience, mode of delivery) were independent variables.

\section{Operational definitions Immediate PPIUCD}

An IUCD that can be inserted post placental, intra cesarean and spontaneous vaginal delivery within $48 \mathrm{~h}$ of delivery.

\section{Utilization of PPIUCD}

Postpartum women who have used postpartum intrauterine contraceptive device.

\section{Good knowledge}

A score of greater than or equal to mean (correct answers for 5 or more out of 10) of knowledge assessment questions.

\section{Poor knowledge}

A score of less than mean of the knowledge assessment questions.

\section{Favorable attitude}

A score of greater than or equal to mean (correct answers for 2.5 or more out of 5) of attitude assessment questions.

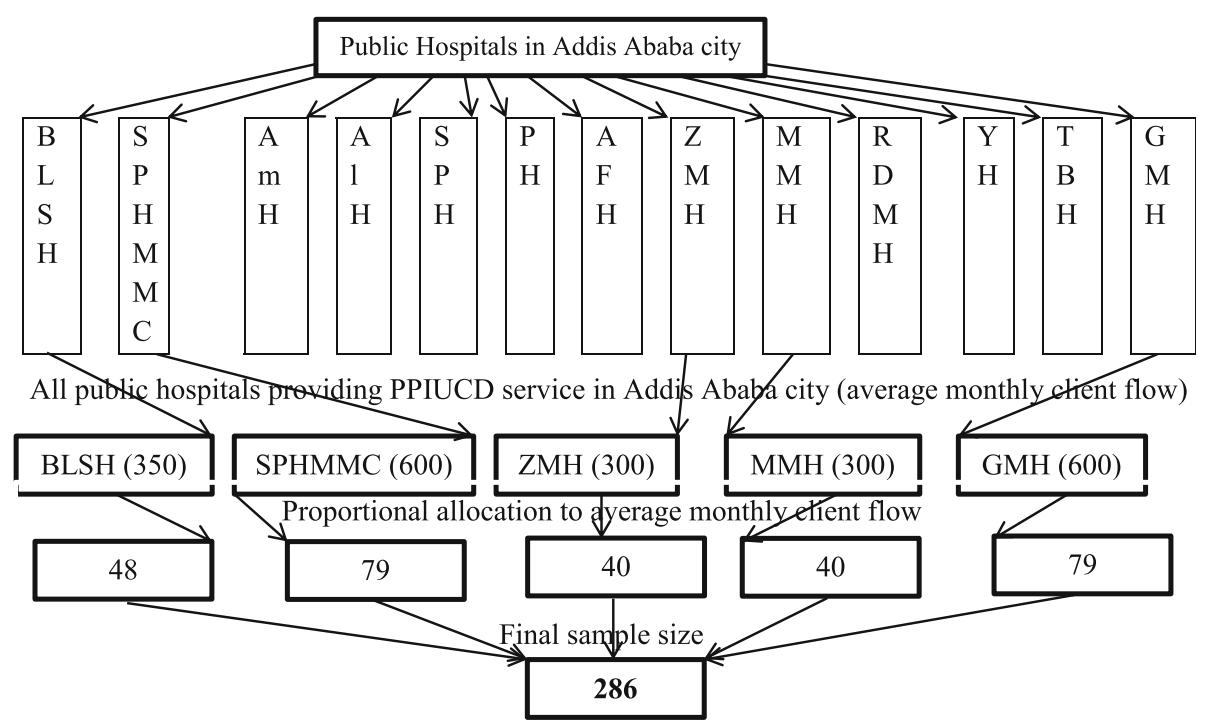

Fig. 1 sampling procedures of study participants in Addis Ababa public hospitals, Addis Ababa, August 25 to September 30,2019 


\section{Unfavorable attitude}

A score of less than mean of the knowledge assessment questions.

\section{Data collection tools and procedures}

A pretested structured interviewer administered questionnaire consisting of items with pre-coded response categories was used. The questionnaire was adopted from EDHS 2016 [27] and reviewing literatures.

The tool has four sections: The first section consists of socio demographic characteristics, second section was about obstetrics related Practice, third section assesses knowledge, fourth section was about attitude and last section was about PPIUCD utilization and related characteristics of study participants. The questionnaire was designed in English and translated in to local Amharic language and then translated back to English by translators for consistency.

Data were collected by face to face interview. Five BSc midwifes for data collection and one MSc midwife for supervision were recruited. One day data collection training was given to data collectors and supervisors on the objectives, benefits of the study, individual's right, informed consent and techniques of the interview.

Before starting the actual data collection to assure the data quality, high emphasis was given to designing data collection instrument. First the questionnaire was pretested on $10 \%$ of sample size, 26 postpartum women in Teklehaymanot general hospital. After pre-test further adjustments on the tool was made to improve clarity, understandability, and simplicity of the messages.

All of the questionnaires were checked for completeness and accuracy before, during and after the period of data collection. Throughout the course of the data collection, interviewers were supervised. Regular meetings were held between the data collectors and the principal investigator to discuss on challenges and solutions of procedures. The collected data was again reviewed and checked for completeness before data entry. Data entry format template was prepared and programmed by principal investigator.

\section{Data analysis}

Data were entered using Epi Data version 4.2, and exported to statistical package of social sciences (SPSS) version 24.0 for analysis. Descriptive statistics were computed to describe study variables in relation to the population. Bivariate and multivariate logistic regression was used to determine the effect of independent variables on immediate PPIUCD utilization. Variables which have $P$ value $<0.2$ on bivariate analysis were selected as a candidate for multivariate analysis. Hosmer-Lemeshow goodness-of-fit test was used to check fitness of the model, and it was best fitted with $P=0.84$. Variables which have $P$-value $\leq 0.05$ on multivariate analysis was considered as statistically significant factors influencing immediate PPIUCD utilization. Finally, results were compiled and presented using texts and tables.

\section{Results}

A total of 286 included respondents were participated in this study, which makes response rate of $100 \%$. About half of the respondents 141(49.3\%) belongs to age category of 25-29 year with mean age of 28.0 and standard deviation of 4.69. Majority of the study participants 271(88.1\%) were married (Table 1$)$.

\section{Obstetrics related practice of study participants}

The mean age at first marriage was 20 year with standard deviation of 3.92. More than two third of

Table 1 Socio-demographic characteristics of post-partum women in Addis Ababa public hospitals, Addis Ababa, August 25 to September 30, 2019- $(N=286)$

\begin{tabular}{|c|c|c|}
\hline Variable & Frequency & Percent (\%) \\
\hline \multicolumn{3}{|l|}{ Age (years) } \\
\hline$\leq 19$ & 4 & 1.4 \\
\hline $20-24$ & 58 & 20.3 \\
\hline $25-29$ & 141 & 49.3 \\
\hline $30-34$ & 47 & 16.4 \\
\hline Above 35 & 36 & 12.6 \\
\hline \multicolumn{3}{|l|}{ Marital Status } \\
\hline Married & 252 & 88.1 \\
\hline Divorced & 20 & 7.0 \\
\hline Unmarried & 6 & 2.1 \\
\hline Widowed & 8 & 2.8 \\
\hline \multicolumn{3}{|l|}{ Level of education } \\
\hline No formal education & 21 & 7.3 \\
\hline Primary (1-8) & 90 & 31.5 \\
\hline Secondary (9-12) & 104 & 36.4 \\
\hline College and above & 71 & 24.8 \\
\hline \multicolumn{3}{|l|}{ Religion } \\
\hline Orthodox & 124 & 43.4 \\
\hline Muslim & 108 & 37.8 \\
\hline Protestant & 46 & 16.1 \\
\hline Catholic & 8 & 2.8 \\
\hline \multicolumn{3}{|l|}{ Occupation } \\
\hline Housewife & 106 & 37.1 \\
\hline Government employee & 28 & 9.8 \\
\hline Private employee & 51 & 17.8 \\
\hline Daily laborer & 20 & 7.0 \\
\hline Self employed & 56 & 19.6 \\
\hline Merchant & 25 & 8.7 \\
\hline
\end{tabular}


study participants $210(73.4 \%)$ had at least one birth. About $81(37.2 \%)$ of the participants had a birth spacing of above 36 months (Table 2).

\section{Knowledge of participants about postpartum intrauterine contraceptive device}

This study showed that more than two third of the study participants $179(68.9 \%)$ of them responded that they have heard IUCD can be inserted immediately after delivery. From the study participants $92.3 \%$ of them answered PPIUD can be removed at any time you wish, followed by $75.5 \%$ who says PPIUCD is inserted free of charge in Ethiopia and $73.4 \%$ of them responded PPIUCD does not cause cancer (Table 3).

\section{Participants attitude about postpartum intrauterine contraceptive device}

The respondents were asked to reflect their opinion on a serious of questions concerning to attitude towards post-partum IUCD. The Likert scale with scores ranging from 1 = disagree to 3 =agree was used to measure their attitude (Table 4).

\section{PPIUCD utilization and related characteristics of study participants}

The study participants ever used family planning methods was 220(76.9\%). Current use of PPIUCD among study participants were $76(26.6 \%)$. All of the study participants were attended ANC visits during current pregnancy and among the women $87(30.4 \%)$ had received family planning counseling (Table 5).

\section{Influencing factors of PPIUCD utilization}

On bivariate analysis age, level of education, occupation, time to have more children, discussion about family planning with partner, needs partner approval to use PPFP, counseled about PPIUCD and knowledge were candidates for multivariate analysis. From this variables Occupation, discuss about FP with partner, needs partner approval to use FP, counseled about PPIUCD and knowledge were remain statistically significant predictors to utilize PPIUCD (Table 6).

From the respondents $81 \%$ of those whose occupation is housewife were $(\mathrm{AOR}=0.19,95 \% \mathrm{CI}$ : 0.06, 0.67) less likely to utilize PPIUCD compared to those who have personal job. In the other hand respondents who have discuss about PPFP with their partner were 1.21times $(\mathrm{AOR}=1.21,95 \% \mathrm{CI}: 1.14,25.67)$ more likely to utilize PPIUCD compared to those who never discuss. Contrarily $81 \%$ of respondents who need partner approval to use PPFP were $(\mathrm{AOR}=0.19,95 \% \mathrm{CI}: 0.05,0.79)$ less likely to utilize PPIUCD compared to those who doesn't need approval. Respondents who have been counseled about PPIUCD were 1.13 times $(\mathrm{AOR}=1.13,95 \% \mathrm{CI}: 1.10$,
Table 2 Obstetric Characteristics of the participants who gave birth in Addis Ababa public hospitals, Addis Ababa, August 25 to September 30, 2019- $(N=286)$

\begin{tabular}{lll}
\hline Variable & Frequency & Percent (\%) \\
\hline $\begin{array}{l}\text { Age at first marriage } \\
\leq 18\end{array}$ & 76 & 26.6 \\
$19-20$ & 86 & 30.1 \\
$21+$ & 124 & 43.4 \\
Number of Birth & & \\
$1-2$ & 210 & 73.4 \\
$3-4$ children & 68 & 23.8 \\
5 and above & 8 & 2.8 \\
Age of last child (months) $(n=218)$ & \\
$\quad<24$ & 62 & 28.4 \\
$24-36$ & 75 & 34.4 \\
$>36$ & 81 & 37.2 \\
Plan to have another child & & \\
Yes & 173 & 60.5 \\
No & 72 & 25.2 \\
Undecided & 41 & 14.3
\end{tabular}

Time to have another child in the future (months) $(n=173)$

$\begin{array}{lll}\text { Less than 24 } & 31 & 17.9 \\ 24-36 & 52 & 30.1 \\ \text { Above 36 } & 90 & 52.0\end{array}$

Number of alive children

$\begin{array}{lll}\text { None } & 4 & 1.4 \\ 1-4 & 210 & 73.4 \\ 5 \text { and above } & 72 & 25.2\end{array}$

Number of children want to have in your life

$\begin{array}{lll}\leq 3 & 106 & 37.1 \\ \geq 4 & 180 & 62.9\end{array}$

present birth planned

$\begin{array}{lll}\text { Yes } & 212 & 74.1 \\ \text { No } & 74 & 25.9\end{array}$

Decision on the use of modern FP

$\begin{array}{lll}\text { Mainly respondents } & 64 & 22.4 \\ \text { Mainly Husband } & 44 & 15.4 \\ \text { Jointly decision } & 178 & 62.2\end{array}$

Discussed on family planning methods with partner during pregnancy

$\begin{array}{lll}\text { Yes } & 133 & 46.5 \\ \text { No } & 153 & 53.5\end{array}$

Partner approves of family planning use

$\begin{array}{lll}\text { Yes } & 113 & 39.5 \\ \text { No } & 173 & 60.5\end{array}$


Table 3 knowledge of postpartum women about PPIUCD in Addis Ababa public hospitals, Addis Ababa, August 25 to September 30, 2019- $(N=286)$

\begin{tabular}{|c|c|c|c|c|c|c|}
\hline \multirow[t]{3}{*}{ Questions } & \multicolumn{4}{|c|}{ Responses } & \multirow{3}{*}{$\begin{array}{l}\text { Correct } \\
\text { responses }\end{array}$} & \multirow{3}{*}{$\begin{array}{l}\text { Percent } \\
\text { correct }\end{array}$} \\
\hline & \multicolumn{2}{|c|}{ TRUE } & \multicolumn{2}{|c|}{ FALSE } & & \\
\hline & $\mathrm{N}$ & $\%$ & $\mathrm{~N}$ & $\%$ & & \\
\hline PPIUD can prevent pregnancies for more than 10 years. & 176 & 61.5 & 110 & 38.5 & TRUE & 61.5 \\
\hline PPIUD is not appropriate for females at high risk of getting STIs. & 147 & 51.4 & 139 & 48.6 & FALSE & 48.6 \\
\hline PPIUD has no interference with sexual intercourse or desire. & 148 & 51.7 & 138 & 48.3 & TRUE & 51.7 \\
\hline PPIUD is immediately reversible (become pregnant quickly when removed). & 182 & 63.6 & 104 & 36.4 & TRUE & 63.6 \\
\hline PPIUD does not cause cancer. & 210 & 73.4 & 76 & 26.6 & TRUE & 73.4 \\
\hline PPIUD can be used by breast feeding mothers. & 202 & 70.6 & 84 & 29.4 & TRUE & 70.6 \\
\hline PPIUD may cause changes in bleeding pattern. & 196 & 68.5 & 90 & 31.5 & TRUE & 68.5 \\
\hline PPIUD can be used by HIV positive patients doing well on treatment. & 117 & 40.9 & 169 & 59.1 & TRUE & 40.9 \\
\hline PPIUD is inserted free of charge in Ethiopia. & 216 & 75.5 & 70 & 24.5 & TRUE & 75.5 \\
\hline PPIUD can be removed at any time you wish. & 264 & 92.3 & 22 & 7.7 & TRUE & 92.3 \\
\hline
\end{tabular}

2.21) more likely to utilize PPIUCD compared to those who were not counseled. Similarly respondents who have good knowledge about PPIUCD were 7.50 times $(\mathrm{AOR}=7.50,95 \% \mathrm{CI}: 4.06,9.31)$ more likely to utilize PPIUCD compared to those who have poor knowledge (Table 6).

Table 4 Attitude of postpartum women about PPIUCD utilization in Addis Ababa public hospitals, Addis Ababa, August 25 to September 30, 2019- $(N=286)$

\begin{tabular}{lll}
\hline Questions & Frequency & Percent (\%) \\
\hline Insertion and removal of PPIUD is highly painful \\
Agree & 234 & 81.8 \\
Not sure & 38 & 13.3 \\
Disagree & 14 & 4.9
\end{tabular}

PPIUCD doesn't move through the body after insertion

$\begin{array}{lll}\text { Agree } & 202 & 70.6 \\ \text { Not sure } & 60 & 21.0 \\ \text { Disagree } & 24 & 8.4\end{array}$

PPIUCD does not interfere with sexual intercourse

$\begin{array}{lll}\text { Agree } & 236 & 82.5 \\ \text { Not sure } & 34 & 11.9 \\ \text { Disagree } & 16 & 5.6\end{array}$

PPIUD is very effective at pregnancy prevention

$\begin{array}{lll}\text { Agree } & 184 & 64.3 \\ \text { Not sure } & 84 & 29.4 \\ \text { Disagree } & 18 & 6.3\end{array}$

PPIUCD can harm a woman's womb

\begin{tabular}{lll} 
Agree & 184 & 64.4 \\
Not sure & 80 & 28.0 \\
Disagree & 22 & 7.7 \\
\hline
\end{tabular}

\section{Discussion}

In this study immediate PPIUCD utilization and influencing factors among participants who gave birth in Addis Ababa public hospitals was assessed. In accordance with immediate PPIUCD utilization knowledge and attitude of participants was studied as an independent predictors. In addition, effect of socio-demographic, obstetric and related factors over PPIUCD utilization was studied.

Immediate PPIUCD utilization among participants who gave birth in Addis Ababa public hospitals was 26.6\% (95\%CI: 21.3, 31.8). Similar figure of PPIUCD utilization was reported in Sidama region, Ethiopia [31] and another study in Rwanda [32]. This is higher than the national report of Ethiopian mini DHS 2019 which is $2 \%$ [22]. Similarly this result is higher than a study done in Sri Lanka 3.4\% [11].

This difference might be due to proportion of women receiving postnatal care in Addis Ababa is higher which is $74 \%$ unlike other part of the country like $10 \%$ in Somali [22]. This might also be due to peoples living in Addis Ababa (capital city of the country) having better route of information. Additionally peoples living in Addis Ababa have different religions whereas Somali region is dominated by Muslim religion followers and the religion prohibits family planning utilization.

From the respondents $81 \%$ of those whose occupation is housewives were less likely to utilize PPIUCD compared to those who have personal job. Similarly a study conducted in Adaba town [33], Bahirdar town [34] and Janamora district [35] house wives were less likely to utilize long acting family planning compared to daily laborers.

This might be due to women's working outside home may have economic difficulties to have additional family member. Additional reasons might be house builders 
Table 5 PPIUCD utilization and related characteristics of participants who gave birth in Addis Ababa public hospitals, Addis Ababa, August 25 to September 30, 2019- $(N=286)$

\begin{tabular}{|c|c|c|}
\hline Variable & Frequency & Percent (\%) \\
\hline \multicolumn{3}{|c|}{ Ever used family planning methods previously } \\
\hline Yes & 220 & 76.9 \\
\hline No & 66 & 23.1 \\
\hline \multicolumn{3}{|c|}{ Family planning use before recent pregnancy $(n=220)$} \\
\hline Yes & 180 & 81.8 \\
\hline No & 40 & 18.2 \\
\hline \multicolumn{3}{|l|}{ Method used $(n=220)$} \\
\hline Natural Family Planning & 7 & 3.2 \\
\hline IUCD & 42 & 19.1 \\
\hline Implanon & 62 & 28.2 \\
\hline Injectable & 76 & 34.5 \\
\hline Pills & 33 & 15.0 \\
\hline \multicolumn{3}{|l|}{ Currently using PPIUCD } \\
\hline Yes & 76 & 26.6 \\
\hline No & 210 & 73.4 \\
\hline \multicolumn{3}{|l|}{ Reason not to use PPIUCD $(n=210)$} \\
\hline wanted to have another child & 31 & 14.8 \\
\hline Not think I could be pregnant & 30 & 14.3 \\
\hline Religion Prohibition & 14 & 6.7 \\
\hline Husband disapproves & 13 & 6.2 \\
\hline Afraid of side effects & 78 & 37.1 \\
\hline Afraid of becoming infertile & 24 & 11.4 \\
\hline Use later when menstruation begins & 20 & 9.5 \\
\hline \multicolumn{3}{|l|}{ Mode of delivery } \\
\hline SVD & 197 & 68.9 \\
\hline Vacuum/ Forceps delivery & 33 & 11.5 \\
\hline $\mathrm{C} / \mathrm{S}$ & 56 & 19.6 \\
\hline \multicolumn{3}{|l|}{ Have antenatal care follow up } \\
\hline Yes & 286 & 100 \\
\hline \multicolumn{3}{|l|}{ Number of antenatal care visits } \\
\hline 1 visit & 2 & 0.7 \\
\hline $2-3$ visits & 42 & 14.7 \\
\hline 4 visits and above & 242 & 84.6 \\
\hline \multicolumn{3}{|l|}{ PPIUCD counseling in the health facilities } \\
\hline Yes & 87 & 30.4 \\
\hline No & 199 & 69.6 \\
\hline \multicolumn{3}{|l|}{ Time of PPIUCD counseling $(n=87)$} \\
\hline During ANC follow up & 69 & 79.3 \\
\hline During labor & 4 & 4.6 \\
\hline After delivery & 14 & 16.1 \\
\hline
\end{tabular}

(house wives) have other source of income unlike daily laborers and others.

Respondents who discuss about PPFP with their partner were more likely to utilize PPIUCD compared to those who never discuss. Consistently a study conducted in Bahirdar town explains that women's who have spousal discussion were utilizing long acting family planning [34].

Respondents who need partner approval to use PPFP less likely to utilize PPIUCD compared to those who don't need approval. Similarly a study conducted in Gamogofa zone public health facilities states that odds of mothers who have partner support for IUCD insertion were more likely to utilize PPIUCD than those do not have partner support [10].

This might be due to women's usually depends on their husband's decision in Ethiopia, even though government and different nongovernmental organizations were working on empowering women. In addition to this it might also be due to take care of their marriage and families from unresolvable quarrels and to prevent divorce. Another description might be decisions made jointly with agreement of both couples will have better outcome since issue of family planning is not only the concern of one partner.

In this study participants who have been counseled about PPIUCD were more likely to utilize PPIUCD compared to those who were not counseled. Similarly a study conducted in Sidama region [31] and Bahirdar town [36] shows counseled clients were dedicated to utilize PPIUCD.

Another clustered randomized data in Tanzania explains that giving women informational materials on PPIUCD and counseling after admission for delivery are likely to increase the proportion of women choosing PPIUCD [19]. In the same manner a study in India assures that counseling in the antenatal period was a key point in increasing acceptance of PPIUCD [37].

This might be because women who are received family planning counseling during $\mathrm{ANC}$ and $\mathrm{PNC}$ might be highly motivated to use PPIUCD. This might also be due to counseling can solve traditional attitudes and myths thinking that PPIUCD is bad. In the other hand counseling can made clients to improve their knowledge about the methods they are going to use. Result of this study verifies that clients who have good knowledge were utilizing PPIUCD.

Respondents who have good knowledge about PPIUCD were more likely to utilize PPIUCD compared to those who have poor knowledge. In the same manner a study conducted in Janamora district [35] and Bahirdar town [34] women who had good knowledge were utilize PPIUCD compared to those who had poor knowledge.

Consistently a study conducted in India states that clients who have good knowledge have better experience 
Table 6 PPIUCD utilization predictors among participants who gave birth in Addis Ababa public hospitals, Addis Ababa, August 25 to September 30, 2019-( $N=286)$

\begin{tabular}{|c|c|c|c|c|}
\hline \multirow[t]{2}{*}{ Variables/Category } & \multicolumn{2}{|l|}{ PPIUCD } & \multirow[t]{2}{*}{$\operatorname{COR}(95 \% \mathrm{Cl})$} & \multirow[t]{2}{*}{$\mathrm{AOR}(95 \% \mathrm{Cl})$} \\
\hline & Utilized N (\%) & Not utilized N (\%) & & \\
\hline \multicolumn{5}{|l|}{$\overline{\text { Age }}$} \\
\hline $15-24$ & $8(10.5)$ & $54(25.7)$ & & \\
\hline $25-34$ & $54(71.1)$ & $134(63.8)$ & $0.37(0.16,0.82)$ & $0.29(0.08,1.14)$ \\
\hline$>35$ & $14(18.4)$ & $22(10.5)$ & $0.23(0.08,0.63)$ & $0.51(0.09,2.76)$ \\
\hline \multicolumn{5}{|l|}{ Level of education } \\
\hline No formal education & $2(2.6)$ & $19(9.0)$ & $5.49(1.18,25.47)$ & $1.87(0.02,34.92)$ \\
\hline Primary (1-8) & $7(9.2)$ & $83(39.5)$ & $6.85(2.76,17.02)$ & $1.61(0.09,4.15)$ \\
\hline Secondary (9-12) & $41(53.9)$ & $63(30.0)$ & $0.89(0.48,1.66)$ & $0.62(0.57,4.62)$ \\
\hline College and above & $26(34.2)$ & $45(21.4)$ & 1 & 1 \\
\hline \multicolumn{5}{|l|}{ Occupation } \\
\hline Housewife & $22(28.9)$ & $84(40.0)$ & $0.76(0.69,2.53)$ & $0.19(0.06,0.67)^{*}$ \\
\hline Employed $^{\mathrm{a}}$ & $28(36.8)$ & $51(24.3)$ & $0.63(0.33,1.19)$ & $0.52(0.15,1.82)$ \\
\hline Personal job ${ }^{\mathrm{b}}$ & $26(34.2)$ & $75(35.7)$ & 1 & 1 \\
\hline \multicolumn{5}{|l|}{ Time to have more child } \\
\hline$<24$ months & $13(29.5)$ & $18(14)$ & $0.39(0.17,0.94)$ & $3.56(0.94,13.81)$ \\
\hline 24-36 months & $11(25)$ & $41(31.8)$ & $1.06(0.46,2.44)$ & $0.98(0.33,2.96)$ \\
\hline$>36$ months & $20(45.5)$ & $70(54.3)$ & 1 & 1 \\
\hline \multicolumn{5}{|c|}{ Discuss about PPFP with partner } \\
\hline Yes & $37(48.7)$ & $116(55.2)$ & $1.30(0.76,2.20)$ & $1.21(1.14,25.67)^{*}$ \\
\hline No & $39(51.3)$ & $94(44.8)$ & 1 & 1 \\
\hline \multicolumn{5}{|c|}{ Needs partner approval to use PPFP } \\
\hline Yes & $51(67.1)$ & $122(58.1)$ & $0.68(0.39,1.18)$ & $0.19(0.05,0.79)^{*}$ \\
\hline No & $25(32.9)$ & $88(41.9)$ & 1 & 1 \\
\hline \multicolumn{5}{|c|}{ Counseled about PPIUCD during pregnancy } \\
\hline Yes & $25(48.7)$ & $88(23.8)$ & $1.16(1.12,2.01)$ & $1.13(1.10,2.21)^{* *}$ \\
\hline No & $39(51.3)$ & $160(76.2)$ & 1 & 1 \\
\hline \multicolumn{5}{|l|}{ Knowledge about PPIUCD } \\
\hline Poor & $66(86.8)$ & $72(34.3)$ & 1 & 1 \\
\hline Good & $10(13.2)$ & $138(65.7)$ & $12.65(6.14,26.08)$ & $7.50(4.06,9.31)^{* * *}$ \\
\hline
\end{tabular}

${ }^{*}=P<0.05,{ }^{* *}=P<0.01,{ }^{* * *}=P<0.001,{ }^{\mathrm{a}}=$ gov't \& private employee, ${ }^{\mathrm{b}}=$ merchant, self-employee and daily laborer

of PPIUCD [38]. In the other hand this study describes that $63.6 \%$ of participants scored mean and above the mean of attitude assessment questions, and considered as having a favorable attitude towards PPIUCD; attitude was not statistically a significant factor to utilize PPIUCD.

\section{Strength and limitation of the study}

This study well presents residence of Addis Ababa city, their stance of utilizing immediate PPIUCD and identify the bottle neck factors for the service. Contrary to this it was conducted in Addis Ababa city (capital city of the country) public hospitals; hence the findings might not be adequately reflected the entire population and other cities of Ethiopia.

\section{Conclusion}

This study concludes that PPIUCD utilization among Addis Ababa city public hospital was high compared to other studies. Participants whose occupation was housewife and who needs partner approval to utilize PPIUCD were less likely to utilize PPIUCD compared to their counter parts. Whereas participants who have discussed about PPIUCD with their spouse, have counseled about PPIUCD during their pregnancy and participants who have good knowledge were more likely to utilize 
PPIUCD compared to their counter parts. Based on this result the following recommendations were given.

- Housewife's need to be supported by Addis Ababa health office and health extension workers to work on PPIUCD utilization by delivering appropriate information.

- Discussion about family planning in the community at large in Ethiopia is not common. There for discussion with partner about family planning need to be a culture and should be encouraged by health professionals working on maternal health services.

- Good counseling can address client myths and misconceptions about the PPIUCD there for health professionals delivering this service should give emphasis for it. Each facilities working on this service should integrating postnatal care with postpartum family planning counseling.

\section{Abbreviations}

AFH: Armed Force Hospital; AlH: Alert Hospital; AmH: Amanuel Hospital; ANC: Antenatal Care; AOR: Adjusted Odds Ratio; BLSH: Black Lion Specialized Hospital; Cl: Confidence Interval; FP: Family Planning; GMH: Gandhi Memorial Hospital; MMH: Menilik II Memorial Hospital; PH: Police Hospital; PNC: Postnatal Care; PPFP: Post Partal Family Planning; PPFP: Postpartum Family Planning; PPIUCD: Post Partal Intrauterine Contraceptive Device; RDMH: Ras-Desta Memorial Hospital; SPH: St Peter Hospital; SPHMMC: St Paul Hospital Millennium Medical College; SPSS: Statistical Package of Social Sciences; STD: Sexual Transmitted Diseases; TBH: Tirunesh Beijing Hospital; WHO: World Health Organization; YH: Yekatite-12 Hospital; ZMH: Zewditu Memorial Hospital

\section{Acknowledgements}

Clients who have been participated were corner stone of this study; thank you for your participation. Addis Ababa University has an indispensible role in funding and arranging situations to conduct this study, thank you instead.

\section{Authors' contributions}

All authors equally participated in this study in all session. The author(s) read and approved the final manuscript.

\section{Funding}

This study was supported by Addis Ababa University. But the university has no role in writing this manuscript, and design, analysis, and interpretation of data.

\section{Availability of data and materials}

The datasets supporting result of this study is available from the corresponding author on reasonable request, but it is not available in public in favor of participant's confidentiality.

\section{Ethics approval and consent to participate}

Ethical clearance was obtained from institutional review board of Addis Ababa University, college of health sciences, School of Nursing and Midwifery research committee. Support letter from School of Nursing and Midwifery were written to all selected hospitals and Addis Ababa city administration Health Bureau.

After information was provided about purpose of the study, noninvasiveness of the data collection procedure, confidentiality of the information and all the participants were reassured. Then, after obtaining informed consent from every participant, the data collectors were continued with giving due respect to the norms, values, beliefs, culture, and ensured confidentiality of clients information.

\section{Consent for publication}

Not applicable.

\section{Competing interests}

The authors declare that they have no competing interests.

\section{Author details}

${ }^{1}$ Department of Midwifery, Wolkite University, Wolkite, Ethiopia. ${ }^{2}$ College of Health Science, Black Lion Specialized Hospital, Addis Ababa University, Addis Ababa, Ethiopia. ${ }^{3}$ School of Nursing and Midwifery, Addis Ababa University, Addis Ababa, Ethiopia.

Received: 18 August 2020 Accepted: 6 January 2021

Published online: 02 February 2021

References

1. Kanakuze CA, Dan K, Musabirema P, Pascal N, Mbalinda SN. Factors Associated with the Uptake of Immediate Postpartum Intrauterine Contraceptive Devices (PPIUCD) in Rwanda: A Mixed Methods Study; 2020. p. 1-15.

2. Goldthwaite LM, Cahill EP, Voedisch AJ, Blumenthal PD. Postpartum intrauterine devices: clinical and programmatic review. Am J Obstet Gynecol. 2018;219(3):235-41.

3. Pearson E, Senderowicz L, Pradhan E, Francis J, Muganyizi P, Shah I, et al. Effect of a postpartum family planning intervention on postpartum intrauterine device counseling and choice: evidence from a clusterrandomized trial in Tanzania. BMC Womens Health. 2020:20(1):1-13.

4. Cwiak C, Cordes S. Postpartum intrauterine device placement: a patientfriendly option. Contracept Reprod Med. 2018:3(1):3-7.

5. Bano Z, Memon S, Khan FA, Shahani MJ, Naz U, Ali SN. Comparative analysis of postpartum IUCD versus interval IUCD insertion: a study conducted in a tertiary care hospital in Karachi. Pakistan Int J Res Med Sci. 2020;8(6):2213.

6. Alem A, Garedew T, Mathewes B, Hasan S, Shannon C, Etheredge A. Introduction of postpartum intrauterine Contraceptive devices for expanding Contraceptive options for postpartum women in Ethiopia; 2018.

7. Fikadu Geda Y, Siyoum M, Tirfie WA. Pregnancy History and Associated Factors among Hawassa University Regular Undergraduate Female Students, Southern Ethiopia; 2020. p. 2020.

8. Geda Y. Determinants of teenage pregnancy in Ethiopia: a case-control study, 2019. Curr Med Issues. 2019;17(4):112.

9. Cooper M, McGeechan K, Glasier A, Coutts S, McGuire F, Harden J, et al. Provision of immediate postpartum intrauterine contraception after vaginal birth within a public maternity setting: health services research evaluation. Acta Obstet Gynecol Scand. 2020;99(5):598-607.

10. Mohammed SJ, Gebretsadik W, Endeshaw G, Shimbre M, Shigaz MKA, Metebo KN, et al. Determinants of postpartum IUCD utilization among mothers who gave birth in Gamo zone public health facilities. Southern Ethiopia: case-control study; 2019. p. 1-2.

11. Dasanayake DLW, Patabendige M, Amarasinghe Y. Single center experience on implementation of the postpartum intrauterine device (PPIUD) in Sri Lanka: a retrospective study. BMC Res Notes. 2020:13(1):4-9.

12. Kumar S, Srivastava A, Sharma S, Yadav V, Mittal A, Kim YM, et al. One-year continuation of postpartum intrauterine contraceptive device: findings from a retrospective cohort study in India. Contraception. 2019;99(4):212-6.

13. Peterson SF, Goldthwaite LM. Postabortion and Postpartum Intrauterine Device Provision for Adolescents and Young Adults. J Pediatr Adolesc Gynecol. 2019;32(5, Supplement):S30-5.

14. Deshpande DSA. Evaluation of safety, efficacy and continuation rates of postpartum intrauterine Contraceptive devices (PPIUCD) (Cu-T 380 a). J Med Sci Clin Res. 2018;6(7):1047-52.

15. Ouyang M, Peng K, Botfield JR, McGeechan K. Intrauterine contraceptive device training and outcomes for healthcare providers in developed countries: a systematic review. PLoS One. 2019;14(7):1-14.

16. Firdous S, Shadab W, Saeed A. Efficacy of Intrauterine Copper T-380A Contraceptive Device in Postpartum Period. J Soc Obstetr Gynaecol Pakistan. 2018;7(4):173-6.

17. Wasim T, Shaukat S, Javed L, Mukhtar S. Outcome of immediate postpartum insertion of intrauterine contraceptive device: experience at tertiary care hospital. J Pak Med Assoc. 2018;68(4):519-25.

18. Makins $\mathrm{A}$, Arulkumaran S. Institutionalization of postpartum intrauterine devices. Int J Gynecol Obstet. 2018:143:1-3.

19. Puri MC, Joshi S, Khadka A, Pearson E, Dhungel Y, Shah IH. Exploring reasons for discontinuing use of immediate post-partum intrauterine device in Nepal: a qualitative study. Reprod Health. 2020;17(1):1-6. 
20. Cullen J, Ali SM. Systematic review of educational interventions to improve the uptake of post-partum intrauterine Contraceptive device (Ppiucd). Pakistan J Public Heal. 2018;7(4):226-31.

21. Access $\mathrm{O}$, Placental $\mathrm{P}$, Contraceptive I, Insertion D, Article $\mathrm{O}$, Armed $\mathrm{P}$, et al. Post placental intrauterine contraceptive device insertion. 2019;69(5):1115-1119.

22. CSA. Ethiopia Mini DHS. 2019.

23. Gonie A, Worku C, Assefa T, Bogale D, Girma A. Acceptability and factors associated with post-partum IUCD use among women who gave birth at bale zone health facilities, Southeast-Ethiopia. Contracept Reprod Med. 2018;3(1). https://doi.org/10.1186/s40834-018-0071-z.

24. Sahu D, Tripathi U. Outcome of immediate postpartum insertion of IUCD - a prospective study. Indian J Obstet Gynecol Res. 2018;5(4):511-5.

25. Cooper M, Cameron S. Successful implementation of immediate postpartum intrauterine contraception services in Edinburgh and framework for wider dissemination. Int J Gynecol Obstet. 2018:143:56-61.

26. de Caestecker L, Banks L, Bell E, Sethi M, Arulkumaran S. Planning and implementation of a FIGO postpartum intrauterine device initiative in six countries. Int J Gynecol Obstet. 2018;143:4-12.

27. CSA, UNICEF E. Ethiopian Demographic and Health Survey 2016. Ethiopia: $\mathrm{MOH} ; 2016$.

28. Cooper M, Boydell N, Heller R, Cameron S. Community sexual health providers' views on immediate postpartum provision of intrauterine contraception. BMJ Sex Reprod Heal. 2018;44(2):97-102.

29. City Government Of Addis Ababa BOFAED. Document. Socio-Economic Profile Of Addis Ababa; 2013.

30. WHO/UNFPA Guidance WHO. 2016

31. Tefera LB, Abera M, Fikru C, Tesfaye DJ. Utilization of immediate postpartum intra uterine Contraceptive device and associated factors: a facility based cross sectional study among mothers delivered at public health facilities of Sidama zone, South Ethiopia. J Pregnancy Child Heal. 2017; 04(03):2-10.

32. Ingabire R, Nyombayire J, Hoagland A, Da Costa V, Mazzei A, Haddad L, et al. Evaluation of a multi-level intervention to improve postpartum intrauterine device services in Rwanda [ version 3 ; referees : 3 approved ] Referee Status : Gates Open Research; 2019. p. 1-27.

33. Fekadu H, Kumera A, Yesuf EA, Hussien G, Tafa M. Prevalence and Determinant Factors of Long Acting Contraceptive Utilization among Married Women of Reproductive Age in Adaba Town, West Arsi Zone, Oromia, Ethiopia. J Women's Heal Care. 2017;06(01)..

34. Tesfa E, Gedamu H. Factors associated with utilization of long term family planning methods among women of reproductive age attending Bahir Dar health facilities, Northwest Ethiopia. BMC Res Notes. 2018;11(1):1-7.

35. Getahun DS, Wolde HF, Muchie KF, Yeshita HY. Utilization and determinants of long term and permanent contraceptive methods among married reproductive age women at Janamora district, Northwest Ethiopia. BMC Res Notes. 2018;11(1):1-6.

36. Animen S, Lake S, Mekuriaw E. Utilization of intra uterine contraceptive device and associated factors among reproductive age group of family planning users in Han health center, Bahir Dar, north West Amhara, Ethiopia, 2018. BMC Res Notes. 2018;11(1):1-6.

37. Pradhan S, Kshatri JS, Sen R, Behera AA, Tripathy RM. Determinants of uptake of post-partum intra-uterine contraceptive device among women delivering in a tertiary hospital, Odisha, India. Int J Reprod Contraception, Obstet Gynecol. 2017;6(5):2017.

38. Yadav S, Joshi R, Solanki M. Knowledge attitude practice and acceptance of postpartum intrauterine devices among postpartal women in a tertiary care center. Int J Reprod Contraception, Obstet Gynecol. 2017:6(4):1507.

\section{Publisher's Note}

Springer Nature remains neutral with regard to jurisdictional claims in published maps and institutional affiliations.

Ready to submit your research? Choose BMC and benefit from:

- fast, convenient online submission

- thorough peer review by experienced researchers in your field

- rapid publication on acceptance

- support for research data, including large and complex data types

- gold Open Access which fosters wider collaboration and increased citations

- maximum visibility for your research: over $100 \mathrm{M}$ website views per year

At $\mathrm{BMC}$, research is always in progress.

Learn more biomedcentral.com/submissions 